\title{
Challenges in Power Production Investment in Vietnam
}

\author{
Nam Hoai Nguyen, Binh Van Doan, Quyen Le Luu and Thanh Cao Nguyen \\ Institute of Energy Science, Vietnam Academy of Science and Technology, 18 Hoang Quoc Viet, Cau Giay, Hanoi 10072, Vietnam
}

\begin{abstract}
This paper presents the results of the survey to initially assess the current situation of power supply chain development in Vietnam. The research team used questionnaires to identify challenges and barriers in power production investment. Surveyors came from power generation units, power transmission and distribution units, service providers for power plants, consulting agency and research institutes. The results indicated that there is a difference among enterprises' barriers and difficulties in the management, finance and investment environment. This difference is related to the business profiles of the enterprise, its segment of the electricity generation market, capacity and experience in the market.
\end{abstract}

Key words: Power production, investment, Vietnam, policy recommendation.

\section{Introduction}

\subsection{General}

The electric power market plays an important role in power sector development of Vietnam. One of the key objectives set out for the development of Vietnamese electric power market is attracting investment from all economic sectors and gradually removing the State investment into the power industry. The electric power market has achieved positive results in terms of the performance capacity, the reliability of the system, basically power supply and demand balance. Besides, the performance of a competitive electric power market has increased the transparency and fairness in mobilizing other resources for power generation. However, there still existed certain restrictions in the market development such as subsidization; difficulty in attracting investment from foreign and private developer, efficiency of the power sector's business activities, the pressure in power price increase and the rights of customers [1,2]. One of the primary causes is the ineffectiveness of investment attraction into the electric power market.

The authors have conducted surveys and interviewed

Corresponding author: Quyen Le Luu, MSc, research field: sustainable energy development. enterprises involved in the field of electricity production in Vietnam to identify the challenges and barriers that these businesses encounter during their investment process in Vietnam. The results of the survey will contribute to the policy recommendation to ease the difficulty and promote private investment in electricity production in Vietnam in the coming time.

\subsection{Overview of Power Supply Chain}

Power supply chain consists of four segments: production, transmission, distribution and retail. In the production segment, the electric power is generated by the process of converting energy from hydroelectric sources, thermal energy, wind energy, geothermal or solar. The power generation is closely related to the primary energy sources such as coal, oil, gas, wind, solar and hydro resources. After being produced at the facility, the power was immediately transported to the customers through the network of transmission and distribution system. The power consuming sectors compose of agriculture-forestry-fishery, construction-industry, commerce-service, residential, and other facilities. Fig. 1 presents the power supply chain of Vietnam power industry.

Power can only be temporarily stored. The cost for storing power in the energy storage system is expensive, therefore, it should be produced at the time and amount 


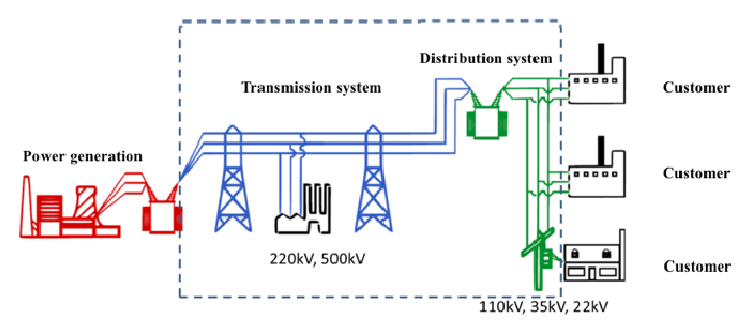

Fig. 1 Power supply chain of Vietnam power industry.

to be suitable to the demand. During the operation of the electric power system, it is compulsory that the production and consumption of electric power are simultaneous and must be always balanced. This is also the fundamental characteristics of the electric power industry which make it totally different from other sectors. If there is any potential of supply-demand imbalance due to supply or demand fluctuations, the power system operator has to apply a special mechanism to ensure that the supply is immediately balanced with the demand.

\subsection{Development of Power Supply}

The power market is operated and developed in accordance to objective principles such as supply and demand laws, competition rules, pricing rules, etc. Besides, the power market has a specific mechanism with several conditions for transactions between buyers and sellers to assure that supply and demand are technically balanced at all times. To meet the above conditions, technical infrastructure for the power market also has unique mechanism, structure and characteristics.

The power market development is the process to improve different components that make the market more completed. This is a synchronous and sustainable development of the basic elements of the market including supply, demand, transmission and distribution infrastructure, trading platforms and mechanisms, and electricity prices. Therefore, unlike most other products, the demand for electricity that grows too fast or is likely to outstrip supply will have a negative impact on the security of the entire power system. This difference needs to be taken into account when studying the power market development.

Power supply and demand is required to be balanced at all times. In case there is an imbalance between the power supply and demand, the power quality of the entire power system will be affected. The demand for electricity must always be fully and instantly met. The higher the consumption, the greater the capacity of production, transmission and distribution, which entails a large capital investment to build more power plants and expand the transmission and distribution infrastructure [3].

It usually takes 5 to 10 years to construct power supply or power transmission and distribution units. The construction of power related projects requires a large investment capital, up hundreds million or billions of USD. Thus, in order to ensure the stable operation of the national and provincial electricity systems with high reliability, the power development plan must always be designed for long term, usually 5 to 10 years or more. In Vietnam, this is the period for the national, provincial or municipal power development plans [3].

\section{Methods}

The research was done in the form of a survey using multiple-choice questionnaires and some open questions. It was conducted from June to August 2017. The survey form was sent to the surveyors through emails. The number of obtained feedback is 24 , including 20 complete responses and 4 incomplete responses. Affiliations of surveyors are presented in Table 1.

Most of the survey participants are representatives of the business that have been investing into the power

Table 1 Affiliation of surveyors.

\begin{tabular}{ll}
\hline Affiliation & $\begin{array}{l}\text { Number of } \\
\text { surveyors }\end{array}$ \\
\hline BOT or IPP power generation businesses & 13 \\
Researchers & 6 \\
EVN related power generation businesses & 2 \\
Transmission businesses or retailers & 2 \\
Service providers for power plants & 1 \\
\hline
\end{tabular}


sector. Some businesses also provide the transmission and distribution services. There are 17 surveyors being developers of solar power projects, wind power projects or both solar and wind power projects. Three surveyors worked for hydropower production businesses, one surveyor worked for biomass power business, and three surveyors worked for businesses operating the coal thermal power.

The survey was designed with several structured questions, used to collect testimonials of people about issues related to difficulties (internal factors) and barriers (external factors) which impact the investment and management of power generation facilities, including renewable energy.

The assessment scale is divided into 5 levels from 1 to 5 . The scale of 1 is perspective to "not difficult" (or "not a barrier") for the business. Vice versa, the scale of 5 means it is "dramatically difficult" (or "significant barrier") for the business.

The authors have designed some open questions to gather the opinions of the surveyors about the macro factors such as business environment, institutional and policy framework, and electric power market. The obtained results played a key part in reviewing the proposed solutions to power market development.

\section{Results}

The survey results showed that the investment into electric power production has encountered the following major obstacles and difficulties, including (i) fuel supply arrangement, (ii) requirements of investment procedures, (iii) completion of construction and grid connection, (iv) arranging investment capital, (v) off-taker and (vi) difficulties from the business environment. These difficulties and barriers are structured into three main groups: difficulties and barriers in management, technique and technology; financial difficulties and barriers; and difficulties and barriers in trading environment in electricity market.

The difference among the barriers and difficulties of enterprises origins from the activities and their involvement in the market. This difference is related to the origin and composition of economic enterprises, power production market segment where they join, ability, qualifications and experience to join the market.

\subsection{Management, Technique and Technology}

Most of the surveyed enterprises found difficulties and barriers in fuel supply arrangement, requirement of investment procedures, completion of construction and grid connection.

Nine to twenty (9-20) surveyed businesses have noticed the difficulties and barriers in arranging material for the operation of the power plant. The barrier of material/fuel arrangement was reported by developers of coal fired power plants and biomass based thermal power plants. Meanwhile, enterprises who invested in hydropower, wind power and solar power expressed that they have many advantages when arranging fuel/source of raw material for the operation of power plants.

The investment procedures (applying for investment certificates, supplementing projects into the power development plan, setting up investment projects, reviewing the environmental impact assessment report, applying for construction permit, and license to operate the power plan, etc.) were the major hurdle for most businesses in the industry, either private enterprises, State enterprises, foreign enterprises or EVN-related enterprises. Fig. 2 presents the perception of enterprises on barrier investment procedures on the scale from 1 to 5 .

The process of completing the construction, grid connection, and management and operation of the power

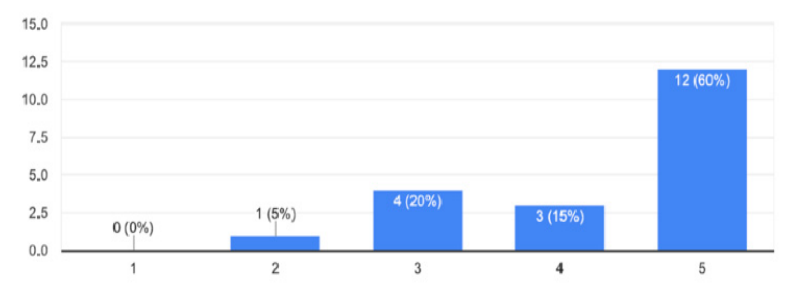

Fig. 2 Barrier on investment procedures. 
plant also caused many difficulties for the business. Thirteen to twenty (13-20) business surveyed who had difficulty in this process (at the scale of 4 and 5), are private enterprises working on renewable power. The few remaining businesses with close connection to EVN or State enterprises have experienced in this process and did not treat this as a barrier. Fig. 3 indicates the difficulty of enterprises during construction completion and grid connection.

\subsection{Economics and Finance}

The majority of surveyed enterprises found difficulties in accessing and mobilizing investment capital for project development; and negotiating and signing contracts/agreements to purchase electricity. Fourteen (14) enterprises encountered significant barriers when approaching and mobilizing investment capital for development of power projects. No enterprises believed that they can smoothly mobilize capital. Only foreign investors and three domestic private investors found it is not significant barrier for them to arrange finance and capital for project development. The perception of capital mobilization difficulty is presented in Fig. 4.

Eighteen to twenty (18-20) surveyed enterprises considered the negotiation and signing of the power purchase agreement as an average-to-big hurdle (scale from 2 to 5), except for two EVN connected enterprises (scale 1). Enterprises, especially private enterprises encounter many difficulties in building and maintaining a team of technical staff, manage the operation of the power plant capacity and qualify to meet the requirements. With the high growth of the electricity production and supply chain in the coming time, the establishment and development of a standard technical team are forecasted to remain great difficulties for businesses who desire to invest in the production of electricity.

\subsection{Business and Investment Environment}

Several businesses ( 9 out of 20) have identified business environment in the power generation is not favorable, not to ensure the transparency in the procedures and investment procedures, licensing. Only a handful of businesses think that the procedures for conducting transactions in the power market are favorable for businesses. Eighteen to twenty (18-20) surveyed businesses expressed that the current policies for managing and operating the electric power market are incomplete. In order to enhance the investment environment in Vietnam, power developers express that there should be supportive mechanism, complete guidelines and regulations. It is also difficult for investors to access the information on policies and power development plans at all levels. The restructure of the power sector and development of the competitive power market has not shown any noticeable results, influencing the investment activities. Besides, it is not really fair for developers who are not connected to EVN to invest into power generation. Businesses' perception of difficulties in investment environment is indicated in Fig. 6.

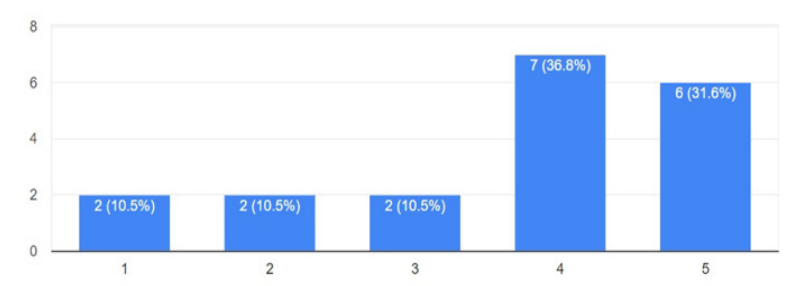

Fig. 3 Difficulty during construction completion and grid connection.

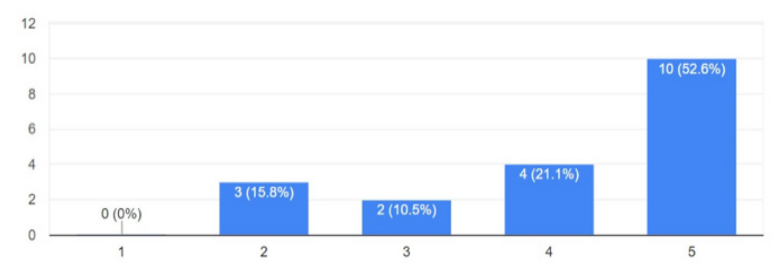

Fig. 4 Difficulty in mobilizing capital.

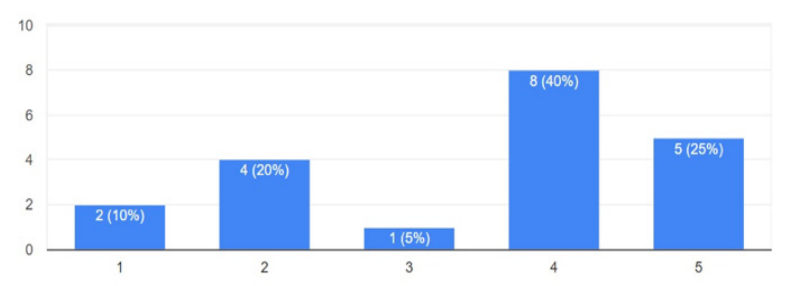

Fig. 5 Difficulty in signing the power purchase agreement. 


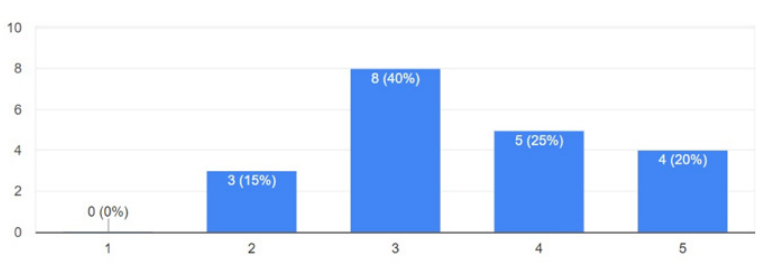

Fig. 6 Assessment of invesment environment.

\section{Conclusion}

The surveyed results indicated that power developers in Vietnam have been facing with several difficulties and barriers during their business investment, deployment and market entry. These difficulties include, but not limited in (i) fuel supply arrangement, (ii) requirements of investment procedures, (iii) completion of construction and grid connection; (iv) arranging investment capital, (v) off-taker and (vi) difficulties from the business environment.

There is a difference between enterprises in perception of barriers and difficulties during their activities and participation in the market. This difference is related to the origin and economic composition of the enterprises, their segment of the electricity generation market, capacity, and experience in the market. EVN related generation companies tend to face difficulties in mobilizing capital. These enterprises also showed good experience and capacity in implementing such procedures as grid connection, operation management, human resource development and negotiation and implementation of power purchase agreements. On the contrary, these are difficult challenges for private sector enterprises. Among the private companies that invest in the electricity generation market, foreign firms have a good capacity in terms of financial capacity, capital mobilization and project management. Surveyed domestic private firms showed that they still face many difficulties to improve their capacity and gain their experience in the studied issues.

In order to attract investment into the Vietnamese power production market, there are some points to be considered, including:

- Further improve the legal and policy framework and reform the administrative procedures to attract investment, especially investment in production infrastructure and electricity grid;

- Enhance the competition, ensure the fairness and transparency in the electric power trading activities and in operation of the electric power market.

- Improve the accessibility to information on planning, investment, license approval procedures for all investors and developers;

- Build capacity and train the high-quality human resources for operating the power trading platform; for construction, operation and maintenance of the power plants and other electric power works, especially renewable power projects.

\section{References}

[1] ERAV. 2015. "The Project of Detailed Designing the Competitive Wholesale Power Market of Vietnam." Ministry of Industry and Trade, Hanoi.

[2] ERAV. 2017. Final Report of Operating the Competitive Power Generation and Wholesale Power Market in the Pilot Period from 01 July 2016 to 30 June 2017. ERAV.

[3] Hiep, D. X. 2012. "Establishment and Development of Power Market in Vietnam." The State research project, Ministry of Science and Technology, Hanoi. 